\title{
Why we eat what we eat. The Eating Motivation Survey (TEMS) ${ }^{\text {is }}$
}

\author{
Britta Renner ${ }^{\mathrm{a}, *}$, Gudrun Sproesser ${ }^{\mathrm{a}}$, Stefanie Strohbach ${ }^{\mathrm{a}}$, Harald T. Schupp ${ }^{\mathrm{b}}$ \\ ${ }^{a}$ University of Konstanz, Psychological Assessment and Health Psychology, Box 47, D-78457 Konstanz, Germany \\ ${ }^{\mathrm{b}}$ University of Konstanz, General Psychology, Box 36, D-78457 Konstanz, Germany
}

\section{A R T I C L E I N F O}

\section{Article history:}

Received 24 November 2011

Received in revised form 4 April 2012

Accepted 7 April 2012

Available online 19 April 2012

\section{Keywords:}

Normal eating

Food choice

Motivation

Assessment

\begin{abstract}
A B S T R A C T
Understanding why people select certain food items in everyday life is crucial for the creation of interventions to promote normal eating and to prevent the development of obesity and eating disorders. The Eating Motivation Survey (TEMS) was developed within a frame of three different studies. In Study 1 , a total of 331 motives for eating behavior were generated on the basis of different data sources (previous research, nutritionist interviews, and expert discussions). In Study 2, 1250 respondents were provided with a set of motives from Study 1 and the Eating Motivation Survey was finalized. In Study 3, a sample of 1040 participants filled in the Eating Motivation Survey. Confirmatory factor analysis with fifteen factors for food choice yielded a satisfactory model fit for a full (78 items) and brief survey version (45 items) with RMSEA .048 and .037, 90\% CI .047-.049 and .035-.039, respectively. Factor structure was generally invariant across random selected groups, gender, and BMI, which indicates a high stability for the Eating Motivation Survey. On the mean level, however, significant differences in motivation for food choice associated with gender, age, and BMI emerged. Implications of the fifteen distinct motivations to choose foods in everyday life are discussed.
\end{abstract}

\section{Introduction}

Understanding why we eat what we eat is essential for understanding 'normal' or 'adaptive' eating behavior. In the past, most research has focused on the pathology of eating such as eating disorders and obesity. Considering that despite treatment, $60 \%$ of patients with an eating disorder maintain clinically significant symptoms (Thompson-Brenner, Glass, \& Westen, 2003) and interventions to reduce body weight often show small or even counterproductive long-term effects (Bacon \& Aphramor, 2011; Mann et al., 2007), primary prevention efforts are particularly important. However, understanding the pathology of eating might tell us very little about how to prevent people from developing dysfunctional eating behaviors. Accordingly, an understanding of 'normal' eating behavior is needed, which goes beyond the absence of dysfunctional eating and encompasses the motives for and functions of eating in everyday life. One possibility for defining normal eating is through a comprehensive characterization of why people eat what they eat, that is by assessing which motives trigger eating behavior in everyday life.

\footnotetext{
Acknowledgements: This research was supported by the Federal Ministry of Education and Research (Grant 0315671, granted to Britta Renner \& Harald Schupp). We thank the German Dietitian Association (VDD) and Verena Klusmann, Alexander Barth, Christoph Becker, Martina Gamp, Helge Giese, Filipa Gonçalves, Freda-Marie Hartung, Norina Kahn, Nicola Liguori, Sophie Raeder, Ralf Schmälzle, David Schubring, and Angela Whale for their valuable support.

* Corresponding author.

E-mail address: britta.renner@uni-konstanz.de (B. Renner).
}

Human eating behavior is regulated by multiple motives. Physiological factors like hunger determine, without question, our eating behavior (Schupp \& Renner, 2011a). Tylka (2006) suggested that adaptive eating, which she termed 'intuitive eating', is predominantly based on physiological hunger and satiety cues rather than situational and emotional cues (cf., Augustus-Horvath \& Tylka, 2011). However, food has an incentive value beyond satiation since the pleasure of eating is also an important motivation for eating (e.g., Jackson, Cooper, Mintz, \& Albino, 2003) and food choice (e.g., Steptoe, Pollard, \& Wardle, 1995). Likewise, positive or negative emotional states (e.g., Macht \& Simons, 2000; Sproesser, Strohbach, Schupp, \& Renner, 2011; Tomiyama, Mann, \& Comer, 2009) or external food cues such as the smell or appearance of food items (e.g., Pollard, Kirk, \& Cade, 2002; Van Strien, Frijters, Bergers, \& Defares, 1986) can trigger eating and food choice. Furthermore, social reasons can prompt eating behavior and food choice since eating together is sociable and often an integral part of social occasions (e.g., Jackson et al., 2003; Pollard et al., 2002). Unobtrusive real-life observations with electronically activated recorders showed that the amount of substantive conversations was significantly related to the time spent eating (Mehl, Vazire, Holleran, \& Clark, 2010). In a similar vein, eating and food choice can also be driven by compliance to social norms and expectations of other people (e.g., Herman, Roth, \& Polivy, 2003; Robinson, Tobias, Shaw, Freeman, \& Higgs, 2011). Thus, in addition to hunger, there are other compelling reasons for us to eat and to choose certain food items.

Most measures to assess motives for eating behavior in everyday life focus on certain core motives. Some focus on reasons for 
eating, such as the Motivations to Eat Scale, which assesses four core motives (to enhance pleasure, to cope with negative affect, to be social, and to comply with others' expectations, Jackson et al., 2003) or the Dutch Eating Behavior Questionnaire (Van Strien et al., 1986) including eating in response to negative emotions (emotional eating) and in response to external sensory cues such as the smell and appearance of food (external eating) as two core motivations to eat. Others focus on both reasons for eating and food choice, such as the Health and Taste Attitudes Questionnaire which quantifies the initiation of eating for the pleasure of taste and choice of foods for health reasons (Roininen, Lähteenmäki, \& Tuorila, 1999). However, many measures focus on food choices in everyday life, whereby motives for eating and food choices can substantially overlap, as in the case of emotional or sensory reasons for eating behavior. Being in a negative mood state, for example, can trigger eating but can also influence the choice of specific foods, i.e. comfort foods. To our knowledge, the most comprehensive conceptualization of food choice motives is the Food Choice Questionnaire developed by Steptoe et al. (1995), which encompasses nine different food choice motives for everyday life (cf., Eertmans, Victoir, Notelaers, Vansant, \& Van den Bergh, 2006; Fotopoulos, Krystallis, Vassallo, \& Pagiaslis, 2009; Januszewska, Pieniak, \& Verbeke, 2011 for factorial validity across countries). In two samples, Steptoe et al. (1995) showed that the good taste, appearance, or smell of food (Sensory Appeal) was rated as the most important motive for food choice. The three motives, with Health reflecting the healthfulness of food items, Price the affordability, and Convenience the accessibility, followed closely in rated importance. Concern over the use of additives, the selection of natural ingredients (Natural Content), and that the food one typically eats helps to control one's weight (Weight Control) were also food choice motives. Similar to emotional triggers of eating (Jackson et al., 2003), Mood emerged as a factor influencing food choice. The two least important food choice motives for participants were Ethical Concerns (e.g. environment friendly packing) and the Familiarity of foods. In a recent cross-country study, Januszewska et al. (2011) found that Sensory Appeal was the most important factor shaping food choice in samples from Belgium, Hungary, and Romania, while Health, Convenience, and Price were among the five most important factors overall. For Filipinos, the most important factors were Health, Price, and Mood, while Sensory Appeal was ranked fourth. Lindeman and Väänänen (2000) extended the nine motives with three value based motives including Ecological Welfare, Political Values, and Religion. However, other important motives for food choice such as social or physiological motives discussed in research are not included in the Food Choice Questionnaire.

Taken together, eating behavior is a complex function of biological, learned, sociocultural, and material-economic factors. Hence, the major goal of the current set of studies was not only to compile the different perspectives provided by existing research on motivations on eating behavior, but also to extend these by including motives identified through nutritionist interviews, discussion groups by psychologists, and the authors' own considerations (Study 1). This procedure aimed to capture a wide-range of motives underlying eating behavior and subsequently develop a concise questionnaire that allows for a comprehensive, systematic, and psychometric sound measurement and investigation of motives for normal eating behavior, i.e. food choice (Study 2 and Study 3 ). In Study 2, the item set was finalized based on psychometric data from a sample of 1250 respondents and theoretical considerations. In Study 3, the Eating Motivation Survey was tested using confirmatory factor analysis in a second sample of 1040 respondents. In order to secure factorial validity, whether the structure of the motives was generally invariant across randomly selected groups, gender, age, and BMI was tested. Additionally, the relative importance of motives was assessed by calculating mean levels across the sample and according to gender, age, and BMI.

\section{Study 1: Generating motives for eating and food choice}

Motives for eating behavior were brought together through a review of previous research, expert interviews with twelve nutritionists, discussions with members of the department of psychology at the University of Konstanz, and considerations by the authors. Specifically, motives were extracted from questionnaires and research on reasons for eating and food choice, whereby questionnaires on eating disorders or directed at children or adolescents were excluded. Motives were extracted from the Food Choice Questionnaire (Steptoe et al., 1995), the Motivations to Eat Scale (Jackson et al., 2003), the Affective and Cognitive Origins of Likings and Dislikes (Letarte, Dube, \& Troche, 1997), the Food Choice Motives among Women questionnaire (Lindeman \& Stark, 1999), the Ethical Food Choice Motives questionnaire (Lindeman \& Väänänen, 2000), the Health and Taste Attitudes Questionnaire (Roininen et al., 1999), the Dutch Eating Behavior Questionnaire (Van Strien et al., 1986; German version: Grunert, 1989), and the Informational Bases of Food Attitudes questionnaire (Aikman, Crites, \& Fabrigar, 2006). We also reviewed the Eating Inventory - also called Three Factor Eating Questionnaire, developed by Stunkard and Messick (1985); German Version: Pudel and Westenhöfer (1989), the Eating Motivation Trait Inventory (Horner, 1998), and the Food Motivation Scale (Martins \& Pliner, 1998), but these did not provide additional motives. The extracted items demonstrated a clear and substantial overlap in terms of the assessed constructs they tap into. In order to compile distinct motives, comparisons were made on item basis, and redundant items were removed from the pool. This resulted in 94 motives out of a total of 241 motives.

Twelve nutritionists from the German Dietitian Association (VDD) were asked about the reasons why people eat and choose certain food items in a semi-structured telephone interview with an open response format. Specifically, the following questions were asked: 'Which are the most important reasons and motives for people to eat?', 'Which other reasons and motives, even uncommon ones, come into your mind?', 'What influences the choice of foods?', 'Which motives and reasons influence the choice of foods in the restaurant/supermarket?'. The interviews lasted 20 min on average and were transcribed verbatim for further analyses. From these transcripts, 209 distinct reasons to eat and to choose certain food items were identified.

Moreover, 28 motives were generated through discussions about why people eat and why they select certain foods with psychologists in the department of psychology at the University of Konstanz. The same questions used in the semi-structured interviews with the nutritionists were used to facilitate the discussions.

In total, 331 reasons to eat and to choose certain food items were generated through the three different sources. Using the Constant Comparative Method (Glaser \& Strauss, 1967), two independent groups of three researchers within the department of psychology sorted these 331 motives into categories by grouping similar motives. In a subsequent session, the two categorization solutions were compared and used to form 26 categories. In a next step, redundancies were removed and up to eight motives were assigned per category in order to create a concise but representative spread of motives. This procedure resulted in a set of 87 motives for eating behavior (all items are available from the authors on request).

\section{Study 2: Development and refinement of the item pool}

In Study 2, the retrieved 87 motives from Study 1 were transformed into a closed-question format. The items were presented 
via an online-questionnaire to 1250 participants and the psychometric characteristics of the items were tested by conducting item analyses and a set of exploratory factor analyses. Final refinement was made on the basis of empirical and content-related reasons (Friedenberg, 1995).

\section{Method}

\section{Participants}

One-thousand five-hundred and six participants filled in an online questionnaire (Unipark survey software, Globalpark AG, Hürth) of the Eating Motivation Survey. Two-hundred fifty-six participants (17\%) filled out less than $75 \%$ of the items and were therefore excluded from analysis.

The remaining 1250 participants (934 women, 75\%) had a mean age of 34 years ( $S D=12$; range 15 to 77 years). Ninety-six percent (1201 participants) were German first-language speakers and 4\% (49 participants) were German second-language speakers. The majority (73\%) had a university-entrance diploma ('Abitur'). Fifty-eight percent were working while $36 \%$ were still in education. The average BMI was $24 \mathrm{~kg} / \mathrm{m}^{2}(S D=4.7$; range 16.3-58.5).

Comparing the study sample $(N=1250)$ with the drop-out sample $(N=256)$ showed no significant differences in terms of BMI $\left[\mathrm{kg} / \mathrm{m}^{2}\right]$ (24 vs. $\left.25, t(1495)=-1.79, p=.074\right)$, education $(73 \%$ vs. $66 \%$ with university-entrance, $\chi^{2}(6)=9.27, p=.159$ ), or working status (58\% vs. $54 \%$ working, $\left.\chi^{2}(4)=2.61, p=.625\right)$. However, the study sample was older (34 vs. 32 years, $t(1499)=2.13$, $p=.033$ ) and included a greater percentage of women (75\% vs. $65 \%, \chi^{2}(1)=9.63, p=.002$ ) than the drop-out sample.

Compared with German population data (Statistische Bundesamt, 2012a,b), the sample was ten years younger, comprised of $24 \%$ more females, and had a slightly lower average BMI (average BMI of the German population is $26 \mathrm{~kg} / \mathrm{m}^{2}$ according to Microcensus data from 2009). In the sample, the employment rate was slightly higher (51\% German population). Moreover, the sample was better educated and the rate of participants in education was higher (26\% of the German population has a university entrance degree; $5 \%$ of the German population is in education).

\section{Procedure}

Participants were recruited through flyers and posters distributed at the University of Konstanz, as well as through links on webpages such as the university webpage or that of a German popular scientific journal (Psychologie Heute). The 87 items for assessing motives for eating behavior were introduced by the following item stem 'I eat because ...' or by 'I select certain foods because ...' and answers were given on a seven-point rating scale from 1 'never' to 7 'always'.

\section{Data analysis}

Missing values were below $5 \%$ for all variables. Missing data were imputed using the Expectation Maximization algorithm in SPSS 17.0 (cf., Gold \& Bentler, 2000). Exploratory factor analyses were conducted using principal axis factoring which reproduces the initial correlation matrix more reliably than other extraction techniques (Thompson, 2004). Promax rotation $(\kappa=4)$, which allows factors to correlate, was applied because earlier research suggests that food choice motives are correlated (e.g., Steptoe et al., 1995). The number of factors to extract was determined by the Kaiser criterion (Kaiser, 1960), parallel analysis (Horn, 1965; O'Connor, 2000), and Velicer's minimum average partial (MAP) test (Velicer, 1976; cf., O’Connor, 2000).

\section{Results}

Assumption testing for exploratory factor analyses

Examining the distribution of the 87 items showed that two items ('I select certain foods for religious reasons.' and 'I select certain foods because I want to gain weight.') were severely skewed ( kew > 3; kurtosis $>10$ ) and were therefore excluded from analysis. No pair of the remaining 85 items correlated above .85 indicating no severe collinearity restrictions. Global diagnostic indicators showed adequate factorability of the correlation matrix with Kaiser-Meyer Olkin $=.91$ and Bartlett's test of sphericity with $\chi^{2}(3570)=53927.15, p<.001$.

\section{Exploratory factor analyses}

A first exploratory factor analysis with the set of 85 items yielded eighteen factors with eigenvalues greater than one. Additionally, the parallel analysis of the eigenvalues suggested the extraction of 13 factors, as did the MAP test. Inspecting the 18factor solution, not a single item loaded highest on the 18th factor, indicating overfactoring. The 13-factor solution both combined parsimony and appeared to fit the data best. One out of 85 items ('I eat when my blood sugar is low, e.g. trembling, feeling weak, headaches.') demonstrated a corrected item-scale correlation lower than .20 and was therefore dropped from further analysis (Bortz \& Döring, 2002). A subsequent factor analysis with the remaining 84 items showed a 13 -factor structure accounting for $49.1 \%$ of the variance, with eigenvalues ranging from 12.9 to 1.3 . To develop a concise questionnaire, five items at maximum per factor with the highest factor loadings were selected. This resulted in the retention of 53 items. An exploratory factor analysis with the 53 items yielded 13 factors with eigenvalues greater than one (ranging from 8.71 to 1.07 ). The 13 factors accounted for $55.4 \%$ of the variance (data are available from the authors on request).

\section{Finalizing the item pool}

In order to finalize the item pool, all 53 items were carefully scrutinized for adequate item characteristics and fit with the content of the respective factor. Specifically, three items with insufficient psychometric characteristics such as low factor loadings $(<.40)$, substantial cross-loading $(>.30)$, or low corrected item-scale correlations $(<.30)$ were deleted. Three items were rephrased in order to increase the fit with the content of the respective scale and two factors which appeared to include two subsets of items, were split accordingly and complemented with two or three new items, respectively (new scales: Pleasure, Liking, Health, Need \& Hunger, cf. Table 1). In order to retain a good representation for each factor, seventeen newly generated items were added. The refinement resulted in total in a set of 78 items grouped into 15 factors (see Table 1 and Appendix for the German version). In order to prevent confounding of item structure and item content, a uniform item stem was adapted for all items.

\section{Study 3: Testing of the Eating Motivation Survey (TEMS)}

The final set of 78 items representing 15 factors was tested by conducting confirmatory factor analyses (CFA) within a sample of 1040 participants. In order to test the consistency of measurement, the 15 factor, 78 indicator model was tested within the total sample as well as within multiple groups (random selection, gender, age, BMI; cf., Kline, 2011). Multiple-group invariance is an indicator for construct validity since it indicates that both the number of factors and the factor-indicator correspondence are the same within each sample (Byrne, 2008; Stein, Lee, \& Jones, 2006). Moreover, 
Table 1

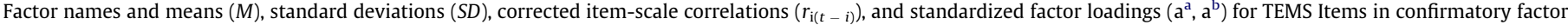
analysis ( $N=1040$, Study 3$)$.

\begin{tabular}{|c|c|c|c|c|c|}
\hline I eat what I eat, ... & $M$ & $S D$ & $r_{i(t-i)^{\mathrm{a}}}$ & $\mathrm{a}^{\mathrm{a}}$ & $a^{b}$ \\
\hline \multicolumn{6}{|l|}{ Liking } \\
\hline$\ldots$ because I think it is delicious & 5.99 & 0.79 & .69 & .76 & \\
\hline ... because I have an appetite for it & 5.68 & 0.89 & .67 & .74 & .71 \\
\hline$\ldots$ because it tastes good & 6.09 & 0.74 & .64 & .71 & .72 \\
\hline .. because I feel like eating it & 5.59 & 0.92 & .62 & .70 & \\
\hline . . because I like it & 5.94 & 0.81 & .63 & .69 & .70 \\
\hline \multicolumn{6}{|l|}{ Habits } \\
\hline$\ldots$ because I eat it regularly & 4.76 & 1.19 & .64 & .74 & \\
\hline ... because $I$ am accustomed to eating it & 4.56 & 1.30 & .63 & .74 & .75 \\
\hline$\ldots$ because I usually eat it & 4.63 & 1.20 & .62 & .71 & .75 \\
\hline ... because it is a set part of my diet & 5.02 & 1.24 & .54 & .57 & \\
\hline$\ldots$ because it is part of my daily diet & 5.03 & 1.27 & .52 & .56 & \\
\hline$\ldots$ because $I$ am familiar with it & 4.78 & 1.16 & .47 & .55 & .60 \\
\hline \multicolumn{6}{|l|}{ Need $\mathcal{E}$ Hunger } \\
\hline . . because I need energy & 4.77 & 1.32 & .37 & .60 & .58 \\
\hline ... because it is pleasantly filling & 4.60 & 1.23 & .34 & .48 & .54 \\
\hline$\ldots$ because it is easy to digest & 4.02 & 1.35 & .18 & .39 & \\
\hline$\ldots$ because I'm hungry & 5.70 & 0.95 & .22 & .31 & .39 \\
\hline \multicolumn{6}{|l|}{ Health } \\
\hline ... to maintain a balanced diet & 4.80 & 1.31 & .67 & .80 & .81 \\
\hline ... because it is healthy & 5.03 & 1.12 & .68 & .80 & .83 \\
\hline ... because it keeps me in shape (e.g. energetic, motivated) & 4.37 & 1.37 & .63 & .70 & .68 \\
\hline$\ldots$ in order to fulfill my need for nutrients, vitamins, and minerals & 4.73 & 1.33 & .63 & .70 & \\
\hline$\ldots$ because it agrees with me & 4.64 & 1.59 & .39 & .44 & \\
\hline \multicolumn{6}{|l|}{ Convenience } \\
\hline ... because it is quick to prepare & 4.68 & 1.21 & .75 & .86 & .87 \\
\hline ... because it is the most convenient & 4.45 & 1.29 & .71 & .82 & .82 \\
\hline$\ldots$ because it is easy to prepare & 4.73 & 1.22 & .70 & .81 & .83 \\
\hline$\ldots$ because it is easy and convenient to purchase & 4.25 & 1.36 & .55 & .60 & \\
\hline ... because it is readily available (e.g. at hand or being offered by someone) & 4.15 & 1.33 & .36 & .39 & \\
\hline \multicolumn{6}{|l|}{ Pleasure } \\
\hline$\ldots$ because I enjoy it & 4.67 & 1.20 & .61 & .71 & .71 \\
\hline$\ldots$ in order to indulge myself & 4.32 & 1.20 & .60 & .69 & .75 \\
\hline$\ldots$ because it puts me in a good mood & 4.08 & 1.42 & .57 & .66 & \\
\hline$\ldots$ in order to reward myself & 3.60 & 1.35 & .53 & .65 & .69 \\
\hline$\ldots$ because it is fun to eat & 4.96 & 1.31 & .43 & .51 & \\
\hline \multicolumn{6}{|l|}{ Traditional Eating } \\
\hline$\ldots$ because it belongs to certain situations & 3.83 & 1.31 & .43 & .72 & .72 \\
\hline ... out of traditions (e.g. family traditions, special occasions) & 3.63 & 1.35 & .49 & .59 & .60 \\
\hline$\ldots$ because I grew up with it & 4.32 & 1.29 & .41 & .54 & .54 \\
\hline$\ldots$ because it fits the season & 4.67 & 1.34 & .16 & .22 & \\
\hline \multicolumn{6}{|l|}{ Natural Concerns } \\
\hline$\ldots$ because it is natural (e.g. not genetically modified) & 4.18 & 1.71 & .82 & .88 & .90 \\
\hline ... because it contains no harmful substances (e.g. pesticides, pollutants, antibiotics) & 4.16 & 1.62 & .80 & .86 & .88 \\
\hline ... because it is organic & 4.13 & 1.56 & .81 & .86 & .82 \\
\hline$\ldots$ because it is fair trade & 3.60 & 1.51 & .76 & .78 & \\
\hline ... because it is environmentally friendly (e.g. production, packaging, transport) & 3.67 & 1.55 & .74 & .77 & \\
\hline \multicolumn{6}{|l|}{ Sociability } \\
\hline$\ldots$ because it is social & 3.81 & 1.39 & .77 & .83 & .88 \\
\hline$\ldots$ so that I can spend time with other people & 3.89 & 1.44 & .75 & .80 & .81 \\
\hline ... because it makes social gatherings more comfortable & 3.88 & 1.37 & .76 & .80 & .75 \\
\hline$\ldots$ because it is pleasant to eat with others & 4.54 & 1.35 & .68 & .73 & \\
\hline$\ldots$ because it makes a social gathering more enjoyable & 3.27 & 1.39 & .64 & .68 & \\
\hline ... because it facilitates contact with others (e.g. at business meals, events) & 3.05 & 1.36 & .62 & .66 & \\
\hline \multicolumn{6}{|l|}{ Price } \\
\hline$\ldots$ because it is inexpensive & 3.95 & 1.38 & .72 & .86 & .90 \\
\hline ... because I don't want to spend any more money & 3.62 & 1.45 & .66 & .79 & .79 \\
\hline ... because it is on sale & 3.66 & 1.39 & .64 & .69 & .64 \\
\hline ... because it is good value for money & 4.34 & 1.34 & .60 & .67 & \\
\hline ... because it is free & 2.80 & 1.46 & .48 & .50 & \\
\hline$\ldots$ because I have already paid for it & 3.82 & 1.47 & .45 & .46 & \\
\hline \multicolumn{6}{|l|}{ Visual Appeal } \\
\hline$\ldots$ because the presentation is appealing (e.g. packaging) & 3.27 & 1.27 & .65 & .77 & .73 \\
\hline ... because it spontaneously appeals to me (e.g. situated at eye level, appealing colors) & 3.49 & 1.36 & .52 & .62 & .67 \\
\hline$\ldots$ because it is nicely presented & 3.99 & 1.30 & .49 & .59 & \\
\hline$\ldots$ because it looks appealing & 4.11 & 1.38 & .49 & .58 & \\
\hline ... because I recognize it from advertisements or have seen it on TV & 2.37 & 1.16 & .40 & .51 & .59 \\
\hline
\end{tabular}


Table 1 (continued)

\begin{tabular}{|c|c|c|c|c|c|}
\hline I eat what I eat, ... & $M$ & $S D$ & $r_{i(t-i)^{\mathrm{a}}}$ & $\mathrm{a}^{\mathrm{a}}$ & $a^{b}$ \\
\hline \multicolumn{6}{|l|}{ Weight Control } \\
\hline ... because I want to lose weight & 3.01 & 1.58 & .83 & .88 & \\
\hline$\ldots$ because it is low in calories & 3.40 & 1.57 & .81 & .85 & .90 \\
\hline ... because I am overweight & 2.79 & 1.58 & .72 & .79 & \\
\hline ... because I watch my weight & 3.70 & 1.64 & .72 & .77 & .74 \\
\hline$\ldots$ because it is low in fat & 3.61 & 1.52 & .69 & .73 & .80 \\
\hline \multicolumn{6}{|l|}{ Affect Regulation } \\
\hline$\ldots$ because I am sad & 2.39 & 1.34 & .84 & .89 & .92 \\
\hline ... because $I$ am frustrated & 2.56 & 1.40 & .81 & .86 & .84 \\
\hline . . because I feel lonely & 2.07 & 1.28 & .75 & .81 & .83 \\
\hline$\ldots$ as a distraction & 2.79 & 1.44 & .73 & .77 & \\
\hline ... because I feel stressed & 3.07 & 1.46 & .73 & .77 & \\
\hline$\ldots$ because it cheers me up & 3.50 & 1.44 & .63 & .66 & \\
\hline \multicolumn{6}{|l|}{ Social Norms } \\
\hline ... because it would be impolite not to eat it & 2.86 & 1.23 & .54 & .67 & .80 \\
\hline ... to avoid disappointing someone who is trying to make me happy & 2.89 & 1.21 & .49 & .62 & .74 \\
\hline$\ldots$ because $I$ am supposed to eat it & 1.95 & 1.08 & .46 & .57 & .50 \\
\hline ... because other people (my colleagues, friends, family) eat it & 2.73 & 1.28 & .37 & .56 & \\
\hline ... because my family/partner thinks that it is good for me & 2.18 & 1.24 & .36 & .41 & \\
\hline ... because my doctor says I should eat it & 1.74 & 1.15 & .20 & .25 & \\
\hline \multicolumn{6}{|l|}{ Social Image } \\
\hline$\ldots$ because it is trendy & 1.77 & 0.91 & .55 & .69 & .68 \\
\hline ... because it makes me look good in front of others & 1.71 & 0.95 & .54 & .66 & .65 \\
\hline$\ldots$ because others like it & 1.93 & 1.03 & .50 & .64 & .66 \\
\hline$\ldots$ to stand out from the crowd & 1.66 & 0.94 & .52 & .56 & \\
\hline$\ldots$ because it is considered to be special & 2.93 & 1.32 & .41 & .49 & \\
\hline
\end{tabular}

Note: Lines in boldface are items selected for the brief TEMS.

a Analysis with all TEMS items.

b Analysis with brief TEMS.

to explore the relative importance of the different motives, mean levels were analyzed in dependence on gender, age, and BMI.

\section{Participants}

One-thousand two-hundred and eighty-four participants took part in an online survey (Unipark survey software, Globalpark AG, Hürth). Two-hundred and forty-four participants (19\%) filled out less than $75 \%$ of the survey and were therefore excluded from analysis. The remaining 1040 participants (745 women, $72 \%$ ) had a mean age of 29 years ( $S D=11$; range $18-77$ years). Ninety-five percent (988 participants) were German first-language speakers and $5 \%$ (52 participants) were German second-language speakers. The majority (89\%) had a university-entrance diploma ('Abitur'). Thirty-four percent were working while $65 \%$ were still in education. The average BMI was $22.8 \mathrm{~kg} / \mathrm{m}^{2}\left(S D=3.9\right.$; range $\left.15.9-64.3 \mathrm{~kg} / \mathrm{m}^{2}\right)$.

Comparing the study sample $(N=1040)$ with the drop-out sample $(N=244)$ showed no significant differences in terms of education $\left(89 \%\right.$ vs. $91 \%$ with university-entrance diploma, $\chi^{2}(5)=4.30$, $p=.508$ ) or working status (65\% vs. $71 \%$ in education, $\chi^{2}(4)=5.15$, $p=.272$ ). However, the study sample was slightly older ( 29 vs. 28 , $t(396.88)=2.53, p=.012)$, had a lower BMI $\left(22.8 \mathrm{vs} .23 .4 \mathrm{~kg} / \mathrm{m}^{2}\right.$, $t(1250)=-2.01, p=.044)$, and included a higher percentage of women $\left(72 \%\right.$ vs. $\left.63 \%, \chi^{2}(1)=6.86, p=.009\right)$ than the drop-out sample.

Compared with German population data (Statistische Bundesamt, 2012a,b), the sample was 15 years younger, comprised of $21 \%$ more females, and had a lower average BMI $\left(26 \mathrm{~kg} / \mathrm{m}^{2}\right.$ German population). In the sample, the employment rate was slightly lower (51\% German population). Moreover, the sample was better educated, and the rate of participants in education was higher (German population: $26 \%$ university entrance degree; $5 \%$ in education).

\section{Procedure}

Using the snowball technique, participants were invited to the study through an E-mail sent to the student and employee register of the University of Konstanz (students $N=9270$; employees $N=2155$ ). Participants were free to forward the link to their acquaintances in order to recruit additional participants. All 78 motives were preceded by the item stem 'I eat what I eat. ..' and answers were given on a 7-point rating scale from 1 'never' to 7 'always'.

\section{Data analysis}

Missing values were below $5 \%$ for all variables. Missing data were imputed using the Expectation Maximization algorithm in SPSS 17.0 (cf., Gold \& Bentler, 2000). Missing values for demographic variables were not imputed (missing $n=1$ for age and $n=7$ for BMI). Confirmatory factor analyses (CFAs) using maximum likelihood solutions were conducted with AMOS 19. The item with the highest factor loading was fixed to 1.0 for each factor, respectively. Model fit was assessed by the comparative fit index (CFI), the standardized root mean squared residual (SRMR), and the root-mean-square error of approximation (RMSEA) as recommend by Kline (2011). A good fit is indicated by a CFI $\geqslant .95$, a SRMR value $\leqslant .08$, and a RMSEA value $\leqslant .06$ (Hu \& Bentler, 1999). Because the $\chi^{2}$ statistic is sample-size dependent, the $\chi^{2} / \mathrm{df}$ ratio was additionally calculated with a $\chi^{2}$ not larger than 2-5 times the degrees of freedom indicating a good fit (Bollen \& Long, 1993). For comparing the fit of models, $\chi^{2}$ difference values were calculated for nested models and AIC for non-nested models with lower values of AIC indicating better fit (Kline, 2011).

\section{Results}

The 15 factors and the means and standard deviations of all 78 items are displayed in Table 1 . Item distributions were inspected for multivariate normality. Skewness and excess of all items were below the thresholds of 2 and 7, respectively, as suggested by Curran, West, and Finch (1996). Since items did not correlate above .85 , no marked collinearity restrictions existed. 
TEMS - full version

The first CFA model tested the hypothesized model with 15 correlated factors and 78 items. Standardized factor loadings and corrected item-scale correlations of all 78 items are listed in Table 1, and fit statistics are displayed in Table 2. Furthermore, factor correlations and internal consistencies are listed in Table 3 while scale means and standard deviations are displayed in Table 4.

As Table 2 shows, the Chi-square statistic was significant $(p<.001)$, indicating no exact fit of the model although this is to be expected considering the large sample size (Kline, 2011). The $\chi^{2} / \mathrm{df}$ ratio, SRMR, and RMSEA, indicate a good approximative model fit, except the CFI which was below the recommended threshold of .95 (Hu \& Bentler, 1999). All 78 items showed a statistically significant factor loading $(p<.001)$, indicating convergent validity. Only the two items 'I eat what I eat because my doctor says I should eat it.' and 'I eat what I eat because it fits the season.' had a factor loading below the recommended level of .30 (Kline, 2011). Moreover, no substantial correlations between either error terms or items located at different factors were observed. Factor correlations were between -.25 (Natural Concerns and Price) and .73 (Social Image and Social Norms) indicating sufficient discriminant validity (cf., Table 3 ). Cronbach's alpha was in the acceptable range for twelve out of the fifteen factors with values greater than .70 (see Table 3). However, the factor 'Social Norms' had an internal consistency of .67, mainly due to a low corrected item-scale correlation of the item 'I eat what I eat because my doctor says I should eat it'. In addition, the two factors 'Traditional Eating' and 'Need \& Hunger' had a low Cronbach's alpha with values below .60, mainly due to three items with a corrected item-scale correlation below .30 (item 'I eat what I eat because it fits the season.' within the Traditional Eating factor and the items 'I eat what I eat because it is easy to digest.' and 'I eat what I eat because I'm hungry.' within the Need \& Hunger factor).

In order to test whether the 15 -factor solution was superior to a more parsimonious 13 -factor model, a 13 -factor model was tested by collapsing the two factors Pleasure and Liking as well as the fac- tors Health and Need \& Hunger into one factor, respectively. The difference between the chi-squares for the two models indicated that the 15-factor model had a significantly smaller chi-square, and thus provided a better fit than the 13-factor model, $\chi^{2}(27)=1284, p<.001$. Also the fit indices yielded a better fit for the 15 -factor model compared to the 13 -factor model.

\section{TEMS - brief version}

In a further step, a brief version of TEMS, including 45 items, was developed (see Table 1). To create a brief version with three items per scale, the minimum possible (cf., Kline, 2011), items were retained by combining the following four criteria (a) high factor loading, (b) no substantial cross-loading on other factors, (c) no correlated error terms, and (d) close fit between item and content of the scale. The model fit for the brief TEMS version was good with a $\chi^{2} / \mathrm{df}$ ratio of $2.44, \mathrm{CFI}=.94, \mathrm{SRMR}=.042$, and $\mathrm{RMSEA}=.037,90 \%$ $\mathrm{CI}=.035-.039$. All factor loadings were significant $(p<.001)$ and greater than .30 (see Table 1). The 15 scales had good reliabilities (see Table 3) with Cronbach's alphas between .90 and .66, except for the Need $\mathcal{E}$ Hunger scale with an internal consistency value of .50 .

Cross-validation: Testing measurement invariance across multiple groups

A stable measurement factor structure across different groups is an important source of evidence for construct validity (Byrne, 2008; Stein et al., 2006). Therefore, a subsequent step tested whether the factor loadings of the full and brief TEMS replicate across randomly divided groups, gender, age, and BMI $\left[\mathrm{kg} / \mathrm{m}^{2}\right]$. Specifically, four group comparisons were made: Random sample $1(n=543)$ compared to random sample $2(n=497)$, women $(n=745)$ compared to men $(n=295)$, participants younger $(n=725)$ and older $(n=314)$ than 30 years of age, and participants with a BMI lower $(n=850)$ and higher $(n=183)$ than $25 \mathrm{~kg} / \mathrm{m}^{2}$.

Table 2

Goodness of fit indices for models of the full and brief TEMS for the total sample $(N=1040)$ and subsamples.

\begin{tabular}{|c|c|c|c|c|c|c|c|c|}
\hline Total sample & $\chi^{2}$ & df & $\chi^{2} / \mathrm{df}$ & CFI & SRMR & RMSEA & $90 \% \mathrm{CI}$ & AIC \\
\hline Model 1: Full version (78 items, 15 factors) & 9498 & 2820 & 3.37 & .83 & .070 & .048 & $.047-.049$ & 10020 \\
\hline Model 2: Factorial reduced version (78 items, 13 factors) & 10782 & 2847 & 3.79 & .80 & .082 & .052 & $.051-.053$ & 11250 \\
\hline Model 3: Brief version (45 items, 15 factors) & 2056 & 841 & 2.44 & .94 & .042 & .037 & $.035-.039$ & 2444 \\
\hline \multicolumn{9}{|l|}{ Random samples (sample 1: $n=543 ;$ sample $2: n=497$ ) } \\
\hline Sample 1: Full version (78 items, 15 factors) & 6418 & 2820 & 2.28 & .82 & .073 & .048 & $.047-.050$ & 6940 \\
\hline Sample 2: Full version (78 items, 15 factors) & 6444 & 2820 & 2.29 & .82 & .074 & .051 & $.049-.053$ & 6966 \\
\hline Sample 1: Brief version (45 items, 15 factors) & 1479 & 841 & 1.76 & .94 & .046 & .037 & $.034-.041$ & 1867 \\
\hline Sample 2: Brief version (45 items, 15 factors) & 1467 & 841 & 1.74 & .94 & .048 & .039 & $.035-.042$ & 1854 \\
\hline \multicolumn{9}{|l|}{ Gender $($ women $n=745 ;$ men $n=295)$} \\
\hline Women: Full version (78 items, 15 factors) & 7680 & 2820 & 2.72 & .82 & .073 & .048 & $.047-.049$ & 8202 \\
\hline Men: Full version ( 78 items, 15 factors) & 5420 & 2820 & 1.92 & .77 & .081 & .056 & $.054-.058$ & 5942 \\
\hline Women: Brief version (45 items, 15 factors) & 1843 & 841 & 2.19 & .93 & .046 & .040 & $.038-.042$ & 2231 \\
\hline Men: Brief version ( 45 items, 15 factors) & 1335 & 841 & 1.59 & .91 & .056 & .045 & $.040-.049$ & 1723 \\
\hline \multicolumn{9}{|l|}{ BMI $\left(<25 \mathrm{~kg} / \mathrm{m}^{2} n=850 ; \geqslant 25 \mathrm{~kg} / \mathrm{m}^{2} n=183\right)$} \\
\hline BMI $<25 \mathrm{~kg} / \mathrm{m}^{2}$ : Full version (78 items, 15 factors) & 8166 & 2820 & 2.90 & .83 & .070 & .047 & $.046-.048$ & 8688 \\
\hline BMI $\geqslant 25 \mathrm{~kg} / \mathrm{m}^{2}:$ Full version (78 items, 15 factors) & 5148 & 2820 & 1.83 & .71 & .091 & .067 & $.064-.070$ & 5670 \\
\hline $\mathrm{BMI}<25 \mathrm{~kg} / \mathrm{m}^{2}$ : Brief version (45 items, 15 factors) & 1752 & 841 & 2.08 & .94 & .042 & .036 & $.033-.038$ & 2140 \\
\hline $\mathrm{BMI} \geqslant 25 \mathrm{~kg} / \mathrm{m}^{2}:$ Brief version (45 items, 15 factors) & 1358 & 841 & 1.61 & .87 & .067 & .058 & $.052-.064$ & 1746 \\
\hline \multicolumn{9}{|l|}{ Age (younger adults $n=725$; older adults $n=314$ ) } \\
\hline Younger: Full version ( 78 items, 15 factors) & 7555 & 2820 & 2.68 & .82 & .069 & .048 & $.047-.049$ & 8077 \\
\hline Older: Full version ( 78 items, 15 factors) & 5372 & 2820 & 1.91 & .80 & .083 & .054 & $.052-.056$ & 5894 \\
\hline Younger: Brief version (45 items, 15 factors) & 1744 & 841 & 2.07 & .93 & .046 & .039 & $.036-.041$ & 2132 \\
\hline Older: Brief version ( 45 items, 15 factors) & 1297 & 841 & 1.54 & .93 & .053 & .042 & $.037-.046$ & 1685 \\
\hline
\end{tabular}

Note: All $\chi^{2}$ are significant at $p<.001$. 
Table 3

Factor correlations and internal consistencies of TEMS $(N=1040)$.

\begin{tabular}{|c|c|c|c|c|c|c|c|c|c|c|c|c|c|c|c|}
\hline & 1 & 2 & 3 & 4 & 5 & 6 & 7 & 8 & 9 & 10 & 11 & 12 & 13 & 14 & 15 \\
\hline 1 Liking & & $.09^{* * *}$ & $.34^{* * * *}$ & $.10^{* * *}$ & $.18^{* * *}$ & $.51^{* * * *}$ & $.15^{* * *}$ & .01 & $.14^{* * * *}$ & .05 & $.25^{* * * *}$ & $-.11^{* * *}$ & .02 & $-.17^{* * * *}$ & $-.13^{* * *}$ \\
\hline 2 Habits & & & $.49^{* * * *}$ & $.22^{* * *}$ & $.32^{* * * *}$ & $.20^{* * * *}$ & $.50^{* * * *}$ & $.09^{*}$ & $.18^{* * * *}$ & $.26^{* * * * *}$ & $.14^{* * * *}$ & $.12^{* * * *}$ & $.15^{* * * *}$ & $.24^{* * * *}$ & $.18^{* * *}$ \\
\hline 3 Need \& Hunger & & & & $.60^{* * *}$ & $.24^{* * *}$ & $.32^{* * * *}$ & $.25^{* * *}$ & $.26^{* * *}$ & $.22^{* * * *}$ & $.18^{* * * *}$ & $.22^{* * * *}$ & .08 & .04 & $.17^{* *}$ & $.10^{*}$ \\
\hline 4 Health & & & & & $-.14^{* * *}$ & $.10^{* *}$ & .04 & $.59^{* * *}$ & $.10^{* *}$ & -.07 & $.08^{*}$ & $.42^{* * *}$ & -.06 & -.03 & .07 \\
\hline 5 Convenience & & & & & & $.20^{* * * *}$ & $.22^{* * * *}$ & $-.13^{* * * *}$ & $.09^{* * *}$ & $.48^{* * * *}$ & $.22^{* * * *}$ & .03 & $.26^{* * *}$ & $.25^{* * * *}$ & $.14^{* *}$ \\
\hline 6 Pleasure & & & & & & & $.60^{* * * *}$ & $.07^{*}$ & $.53^{* * * *}$ & $.21^{* * * *}$ & $.59^{* * * *}$ & $.12^{* * *}$ & $.55^{* * * *}$ & $.33^{* * * *}$ & $.33^{* * *}$ \\
\hline 7 Traditional Eating & & & & & & & & .06 & $.73^{* * *}$ & $.23^{* * * *}$ & $.57^{* * *}$ & $.17^{* * *}$ & $.40^{* * * *}$ & $.64^{* * * *}$ & $.55^{* *}$ \\
\hline 8 Natural Concerns & & & & & & & & & $.16^{* * *}$ & $-.25^{* * *}$ & .07 & $.10^{* *}$ & .01 & .02 & $.14^{* * *}$ \\
\hline 9 Sociability & & & & & & & & & & $.18^{* * * *}$ & $.55^{* * * *}$ & $.09^{* *}$ & $.27^{* * * *}$ & $.55^{* * * *}$ & $.50^{* * *}$ \\
\hline 10 Price & & & & & & & & & & & $.26^{* * *}$ & $.12^{* * *}$ & $.22^{* * *}$ & $.34^{* * * *}$ & $.19^{* *}$ \\
\hline 11 Visual Appeal & & & & & & & & & & & & $.19^{* * * *}$ & $.35^{* * *}$ & $.51^{* * * *}$ & $.50^{* *}$ \\
\hline 12 Weight Control & & & & & & & & & & & & & $.32^{* * * *}$ & $.21^{* * * *}$ & $.20^{* * *}$ \\
\hline 13 Affect Regulation & & & & & & & & & & & & & & $.45^{* * * *}$ & $.33^{* * *}$ \\
\hline 14 Social Norms & & & & & & & & & & & & & & & $.73^{* * *}$ \\
\hline 15 Social Image & & & & & & & & & & & & & & & \\
\hline$\alpha^{\mathrm{a}}$ & .84 & .81 & .48 & .80 & .81 & .77 & .58 & .92 & .89 & .82 & .75 & .90 & .91 & .67 & .73 \\
\hline$\alpha^{\mathrm{b}}$ & .75 & .74 & .50 & .81 & .88 & .71 & .66 & .90 & .85 & .82 & .70 & .85 & .86 & .71 & .70 \\
\hline
\end{tabular}

$p<.05$.

*** $p<.01$.

$p<.001$.

a TEMS.

b Brief TEMS.

Table 4

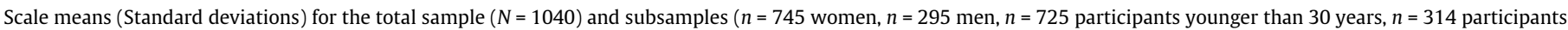
aged 30 or older, $n=850$ participants with BMI lower than $25 \mathrm{~kg} / \mathrm{m}^{2}$, and $n=183$ participants with BMI of $25 \mathrm{~kg} / \mathrm{m}^{2}$ or higher).

\begin{tabular}{|c|c|c|c|c|c|c|c|c|c|c|}
\hline & Overall & Women & Men & $t$ & $<30$ years & $\geqslant 30$ years & $t$ & $\mathrm{BMI}<25$ & $\mathrm{BMI} \geqslant 25$ & $t$ \\
\hline Liking & $5.86(0.65)$ & $5.91(0.64)$ & $5.72(0.67)$ & $4.31^{* * * *}$ & $5.92(0.63)$ & $5.71(0.68)$ & $-4.91^{* * *}$ & $5.89(0.66)$ & $5.69(0.61)$ & $3.88^{* * *}$ \\
\hline Habits & $4.80(0.88)$ & $4.82(0.87)$ & $4.74(0.90)$ & 1.35 & $4.77(0.89)$ & $4.85(0.86)$ & 1.35 & $4.79(0.90)$ & $4.80(0.81)$ & -0.16 \\
\hline Need \& Hunger & $4.77(0.76)$ & $4.83(0.72)$ & $4.62(0.84)$ & $3.90^{* * *}$ & $4.81(0.75)$ & $4.70(0.78)$ & $-2.14^{*}$ & $4.80(0.78)$ & $4.66(0.69)$ & $2.18^{*}$ \\
\hline Health & $4.71(1.01)$ & $4.86(0.92)$ & $4.34(1.12)$ & $7.12^{* * * *}$ & $4.65(1.01)$ & $4.85(1.00)$ & $2.85^{* *}$ & $4.75(1.00)$ & $4.56(1.04)$ & $2.26^{*}$ \\
\hline Convenience & $4.45(0.97)$ & $4.48(0.95)$ & $4.38(1.02)$ & 1.60 & $4.53(0.95)$ & $4.27(0.99)$ & $-4.01^{* * * *}$ & $4.47(0.97)$ & $4.39(0.98)$ & 1.03 \\
\hline Pleasure & $4.33(0.94)$ & $4.42(0.88)$ & $4.08(1.03)$ & $5.12^{* * *}$ & $4.40(0.92)$ & $4.15(0.95)$ & $-3.95^{* * *}$ & $4.33(0.94)$ & $4.31(0.91)$ & 0.22 \\
\hline Traditional Eating & $4.11(0.88)$ & $4.20(0.86)$ & $3.89(0.90)$ & $5.07^{* * *}$ & $4.15(0.88)$ & $4.02(0.86)$ & $-2.22^{*}$ & $4.10(0.88)$ & $4.17(0.87)$ & -1.03 \\
\hline Natural Concerns & $3.95(1.38)$ & $4.11(1.29)$ & $3.53(1.50)$ & $5.89^{* * * *}$ & $3.75(1.38)$ & $4.40(1.26)$ & $7.40^{* * * *}$ & $3.96(1.38)$ & $3.85(1.38)$ & 0.94 \\
\hline Sociability & $3.74(1.10)$ & $3.80(1.08)$ & $3.58(1.16)$ & $2.97^{* *}$ & $3.77(1.10)$ & $3.65(1.11)$ & -1.64 & $3.74(1.12)$ & $3.74(1.04)$ & 0.02 \\
\hline Price & $3.70(1.03)$ & $3.69(1.00)$ & $3.71(1.09)$ & -0.28 & $3.85(1.00)$ & $3.34(1.00)$ & $-7.60^{* * * *}$ & $3.69(1.03)$ & $3.77(1.04)$ & -1.02 \\
\hline Visual Appeal & $3.45(0.91)$ & $3.58(0.87)$ & $3.10(0.92)$ & $8.00^{* * * *}$ & $3.49(0.89)$ & $3.35(0.95)$ & $-2.26^{*}$ & $3.45(0.92)$ & $3.44(0.87)$ & 0.11 \\
\hline Weight Control & $3.30(1.34)$ & $3.56(1.18)$ & $2.65(1.26)$ & $10.34^{* * * *}$ & $3.28(1.37)$ & $3.36(1.25)$ & 0.95 & $3.19(1.35)$ & $3.80(1.15)$ & $-6.32^{* * *}$ \\
\hline Affect Regulation & $2.73(1.15)$ & $2.94(1.16)$ & $2.20(0.95)$ & $10.57^{* * *}$ & $2.81(1.16)$ & $2.53(1.11)$ & $-3.63^{* * * *}$ & $2.65(1.11)$ & $3.07(1.29)$ & $-4.05^{* * *}$ \\
\hline Social Norms & $2.39(0.74)$ & $2.40(0.73)$ & $2.36(0.76)$ & 0.84 & $2.42(0.73)$ & $2.32(0.74)$ & $-1.97^{*}$ & $2.37(0.73)$ & $2.49(0.77)$ & $-2.08^{*}$ \\
\hline Social Image & $2.00(0.72)$ & $1.98(0.70)$ & $2.05(0.78)$ & -1.40 & $2.04(0.72)$ & $1.91(0.71)$ & $-2.64^{* *}$ & $1.98(0.71)$ & $2.08(0.80)$ & -1.52 \\
\hline
\end{tabular}

$\mathrm{BMI}=\mathrm{kg} / \mathrm{m}^{2}$

${ }^{*} p<.05$.

$p<.01$.

$p<.001$.

As a first step, base line model fit was examined for each group separately. Fit indices indicated well-fitting models for the eight groups (see Table 2). In a second step, the invariance of the factor structure across groups was tested by comparing the initial twogroup model, with no imposed equality constraints, with a model where factorial loadings were constrained to be equal across the two comparison groups, respectively (cf. Byrne, 2008; Thompson, 2004).

\section{Random samples}

The goodness of fit of the model for the two groups in combination and with no equality constraints imposed was satisfactory $\left(\chi^{2}=12862, \mathrm{df}=5640, p<.001, \chi^{2} / \mathrm{df}=2.28, \mathrm{CFI}=.82, \quad \mathrm{SRMR}=\right.$ .073 , RMSEA $=.035,90 \% \mathrm{CI}=.034-.036)$. The model with factor loadings constrained to be equal across groups yielded $\chi^{2}=12928, \mathrm{df}=5703, p<.001, \chi^{2} / \mathrm{df}=2.27, \mathrm{CFI}=.82$, SRMR $=.073$, RMSEA $=.035,90 \% \mathrm{CI}=.034-.036$. The two models did not differ significantly $\left(\Delta \chi^{2}=65, \Delta d f=63, p=.399\right)$, indicating that the fac- tor loadings related to the full version of TEMS were invariant. From the perspective of cross-validation, this equality across the two random groups serves as support for the 15-factor TEMS model. Similarly, invariance in measurement could be secured across the two random groups for the brief TEMS.

\section{Gender}

The goodness of fit of the model for the females and males in combination and with no equality constraints imposed was satisfactory $\left(\chi^{2}=13100, \mathrm{df}=5640, p<.001, \chi^{2} / \mathrm{df}=2.32, \quad\right.$ CFI $=.81$, $\mathrm{SRMR}=.073$, RMSEA $=.036,90 \% \mathrm{CI}=.035-.036)$. The model with the factor loadings constrained to be equal across groups yielded $\chi^{2}=13172, \mathrm{df}=5703, p<.001, \chi^{2} / \mathrm{df}=2.31, \mathrm{CFI}=.81, \mathrm{SRMR}=.073$, RMSEA $=.036,90 \% \mathrm{CI}=.035-.036$. The two models did not differ significantly $\left(\Delta \chi^{2}=72, \Delta \mathrm{df}=63, p=.207\right)$, indicating measurement invariance. Similarly, invariance in measurement could be secured across the female and male sample for the brief TEMS version. 
Invariance in measurement weights was also found when comparing participants with a BMI lower and higher than $25 \mathrm{~kg} / \mathrm{m}^{2}$ $\left(\chi^{2}=13314, \mathrm{df}=5640, p<.001, \chi^{2} / \mathrm{df}=2.36, \mathrm{CFI}=.81, \mathrm{SRMR}=.070\right.$, RMSEA $=.036,90 \% \mathrm{CI}=.036-.037$ for the unconstrained model and $\chi^{2}=13390, \mathrm{df}=5703, p<.001, \chi^{2} / \mathrm{df}=2.35, \mathrm{CFI}=.81, \mathrm{SRMR}=.070$, RMSEA $=.036,90 \% \mathrm{CI}=.035-.037$ when factorial loadings were constrained to be equal; $\Delta \chi^{2}=76, \Delta \mathrm{df}=63, p=.121$ ). Highly comparable results emerged for the brief TEMS version (see Table 2 ).

Age

Testing invariance in measurement weights across age yielded a significant difference between the constrained and the unconstrained model, with the latter yielding a significantly better fit to the data with $\Delta \chi^{2}=108, \Delta \mathrm{df}=63, p<.001$ (constrained model: $\chi^{2}=13035, \mathrm{df}=5703, p<.001, \chi^{2} / \mathrm{df}=2.29, \mathrm{CFI}=.81, \mathrm{SRMR}=.069$, RMSEA $=.035,90 \% \mathrm{CI}=.034-.036$; unconstrained model: $\chi^{2}=12927, \mathrm{df}=5640, p<.001, \chi^{2} / \mathrm{df}=2.29, \mathrm{CFI}=.82, \mathrm{SRMR}=.069$, RMSEA $=.035,90 \% \mathrm{CI}=.035-.036$ ). When comparing the two models for participants younger and older than 30 years, differences in unstandardized factor loadings appeared in the three scales: Liking, Visual Appeal, and Price. For older participants, the factor Liking was defined by the items 'I eat what I eat because I have an appetite for it.' and '. . . because I feel like eating it.', while for younger participants, the item '... because it tastes good.' loaded higher on this factor. Similarly, the factor Visual Appeal was defined by the item '... because it looks appealing.' for older participants, while the item '... because I recognize it from advertisements or have seen it on TV.' loaded higher on this scale for younger participants. Furthermore, the factor Price was defined by the item '. . . because it is free.' in the younger sample, while in the older sample the item '. . . because it is good value for money.' loaded higher on this factor. When factor loadings of these seven items were not constrained to be equal across age groups, the model fit did not differ significantly from the unconstrained model with $\Delta \chi^{2}=69, \Delta d f=56, p=.115$.

\section{Relative importance of motives: Mean-level differences between motives}

In order to explore the relative importance of the 15 different motives, data were analyzed using repeated measures ANOVA with 'motives' as within-subjects factor. Mauchly's test indicated that the assumption of sphericity was violated $\left(\chi^{2}(104)=3976\right.$, $p<.001)$; therefore, degrees of freedom were corrected using Greenhouse-Geisser estimates of sphericity $(\varepsilon=0.60)$. The main effect of the motives was significant: $F(8.44,8767.1)=1348.97$, $p<.001, \eta_{\mathrm{p}}{ }^{2}=.57$. Post hoc analyses using the Scheffé post hoc criterion for significance indicated that almost all means of the 15 motives differed significantly with a mean difference of $\geqslant 0.16$, $p<.05$ (see Table 4).

An additional mixed-design ANOVA with motives as a withinsubject factor and gender (male, female), age ( \pm 30 years of age), and BMI $\left( \pm 25 \mathrm{~kg} / \mathrm{m}^{2}\right)$ as between-subjects factors also revealed a main effect for the within-subject factor motives, $F(8.74$, $8958.16)=653.99, p<.001, \eta_{\mathrm{p}}{ }^{2}=.390$, which was qualified by an interaction between motives and gender, $F(8.74,8958.16)=13.84$, $p<.001, \eta_{\mathrm{p}}{ }^{2}=.013$, an interaction between motives and BMI, $F(8.74,8958.16)=11.25, p<.001, \eta_{\mathrm{p}}^{2}=.011$, and an interaction between motives and age, $F(8.74,8958.16)=14.14, p<.001$, $\eta_{\mathrm{p}}{ }^{2}=.014$. No other interactions involving the factor motives were significant, $p>.05$.

Additional analysis showed that women had, on average, significantly higher values than men on 10 of the 15 scales, i.e., Natural Concerns, Affect Regulation, Weight Control, Sociability, Pleasure,
Liking, Visual Appeal, Need \& Hunger, Health, and Traditional Eating (cf., Table 4). Repeating the analyses for the brief TEMS revealed highly comparable results. Participants with a BMI lower than $25 \mathrm{~kg} / \mathrm{m}^{2}$ differed from participants with BMI higher than $25 \mathrm{~kg} /$ $\mathrm{m}^{2}$ on six out of the 15 scales. Specifically, overweight or obese participants had significantly higher scale means on the scales Affect Regulation, Weight Control, and Social Norms, while normal weight participants scored significantly higher on the scale Liking, Need \& Hunger, and Health. Virtually the same pattern of results was found for the brief TEMS, except that the difference on the Social Norms scale was no longer statistically significant. Participants aged 30 or older had significantly higher scale means than younger participants for Natural Concerns and Health, while participants younger than 30 had higher values for Affect Regulation, Convenience, Pleasure, Liking, Visual Appeal, Price, Need \& Hunger, Social Image, Social Norms, and Traditional Eating. Repeating these analyses for the brief TEMS version yielded a virtually unchanged pattern of results.

\section{Discussion}

In the present study series, a comprehensive questionnaire assessing why we eat what we eat in everyday life was developed. The Eating Motivation Survey (TEMS) encompasses 15 factors represented by 78 items (see also Table 1 ).

Liking consists of statements related to palatability of food items, Visual Appeal depicts a motivation to choose food items because of an appealing presentation, Pleasure encompasses motives related to please oneself through food, Affect Regulation is characterized by a tendency to choose certain food items due to a negative affective state, and Need $\mathcal{E}$ Hunger describes eating motivation due to physiological needs. Other factors represent motives in relation to the social context of eating. Sociability encompasses social reasons for food choice, Social Norms comprises food choice to meet others' expectations, and the factor Social Image is characterized by the consumption of food to present oneself positively in social contexts. The motivation to choose food items low in fat or calories to control one's body weight is captured by the factor Weight Control, and the factor Health comprises a motivation to choose food items which are healthy and increase wellness. The factor Price comprises financial reasons for food choice, and Convenience captures the motivation to choose food items which are fast and easy to access with minimal effort. Habits comprises food choices due to familiarity and routines, and Traditional Eating depicts choosing foods out of traditional and circumstances related reasons. Ethical aspects of food choice are captured by the factor Natural Concerns which assesses the preference for natural foods from fair trade or organic farming. Overall, TEMS allows a fine-grained characterization of motives associated with food choice.

\section{Eating motives}

Through the systematization of a considerable wealth of different conceptions and measurements of motives for eating and food choice on a conceptual and empirical basis, a stable factorial structure of motives across different groups (random sample, age, gender, BMI) was generated. While most motives originating in the presented studies have been suggested by previous research, multiple motives were rarely conceptualized and conjointly assessed. Interestingly, by conjointly assessing motives proposed in different questionnaires, new motive factors emerged, tapping across different measures and questionnaires. For example, the TEMS scale Natural Concerns includes items from two different questionnaires: the aspect of ecological welfare from the Ecological Welfare scale 
(Lindeman \& Väänänen, 2000) as well as concerns about the ethics and the natural content of food as suggested by the Food Choice Questionnaire (Steptoe et al., 1995). An examination of the content of the single items from the newly combined scale supports the empirical notion of a consistent and meaningful scale. Conversely, two other motives related to ethical food choice, Political Values and Religion, as proposed by Lindeman and Väänänen (2000), could not be retrieved. However, this does not imply that political or religious values do not impact food choice and eating, rather it suggests that these beliefs and attitudes might be more distal, probably exerting their influence through higher-order factors such as ethical concerns or traditions. Alternatively, the type and importance of political values and religion might vary more strongly across groups as compared to other values; and therefore, they did not emerge as a higher-order factor. However, the vast majority of the participants was German first-language speaker and was probably of White European origin. Being rather homogeneous in terms of cultural background, political values, and religious beliefs, this sample might have restricted variance in political values, religious beliefs, and traditions. Admittedly, this is highly speculative and needs to be addressed in future research.

Importantly, the present data clearly support previous research in replicating specific motives; thereby, suggesting that these might be core, higher-order motives of food choice. Specifically, motives revolving around the topics of health and body weight control seem to represent universal motives, at least in Westernized samples. These motives have been found in many previous studies and are represented in various questionnaires such as the Food Choice Questionnaire (Steptoe et al., 1995) and the Food Choice Motives among Women questionnaire (Lindeman \& Stark, 1999) as well as in studies using implicit measures (Schupp \& Renner, 2011b). Likewise, affect regulation, economic reasons (i.e., price), and convenience aspects appear to emerge in different samples and measures, also suggesting a high reliability as a distinct type of motivation. Furthermore, motives addressed by Jackson and colleagues (2003) and Herman et al. (2003, cf., Robinson et al., 2011), i.e. eating for pleasure, to be sociable, and to meet social norms were supported by the present data.

Posing the open-ended question 'Why do you eat what you eat?' often results in the answer 'Because I am hungry, what else?'. However, the present data suggest that one of the most basic and important types of motives for eating, hunger, is difficult to represent psychometrically. Hunger is included in the factor Need \& Hunger which also encompasses aspects of satiety and energy consumption (see Table 1). However, the factor loading is rather low, and as a consequence, the scale has an unsatisfactory Cronbach's alpha of below .60. This may explain why other questionnaires for assessing motives for eating and food choice in everyday life do not include this basic motive. The only scale in which this concept is addressed is the Intuitive Eating Scale (Tylka, 2006), which measures eating for physical and emotional reasons. However, the focus of the items is on emotional eating rather than eating triggered by physical cues. Moreover, the scale that assesses a reliance on internal hunger and satiety cues captures the capacity to recognize states of hunger and satiety rather than hunger as motive for eating. Likewise, hunger scales are included in questionnaires developed for the investigation of eating disorders such as the Three Factor Eating Questionnaire (Stunkard \& Messick, 1985) or the Food Craving Questionnaire (Cepeda-Benito, Gleaves, Williams, \& Erath, 2000; cf., also Meule, Lutz, Vögele, \& Kübler, 2012). However, these scales focus on craving for food and the circumstances surrounding excessive consumption which is a broader concept and taps more into the '... extremes of dietary restraint' as Stunkard and Messick (1985, p. 71) described it than into normal eating in everyday life.

The importance of hunger as an eating motive in everyday life is strongly supported by the present data since it was one of the most often endorsed items (cf., Table 1) and constituted the third greatest reason for eating behavior. Accordingly, we would like to argue that hunger is 'simply hunger' as Jackson et al. (2003) put it, representing a unique, monofaceted motive which by definition obscures assessment through classical psychometric scales, but which nonetheless, needs to be included in a comprehensive measurement of eating motives.

Another motive which emerged from the present data pertains to social image considerations as triggers of eating and food choice. Although it is not among the most highly ranked motives in the array of the 15 different motives, it appears that the social image of food might be an influential factor in social situations. The phenomenon that people are willing to pay comparably high prices for products which they do not find particularly palatable (i.e., caviar) finds its explanation in the idea that people assume that they can acquire a positive social image by consuming certain food items. Studies on impression management showed that people do change their eating behavior in order to convey a certain impression (Herman et al., 2003). However, one could speculate that this motive is rather implicit, and therefore, people may not be fully aware of their own intentions in this regard (Herman et al., 2003; Robinson et al., 2011).

The interrelation between the factors suggests sufficient divergent validity (cf., Table 3). However, it seems to be evident that certain motives cluster more closely together than others. Interestingly, social image concerns showed a clear co-variation with other sociocultural motives. Social image concerns seem to co-vary with the importance of social norms, traditions, and sociability for triggering and shaping eating behavior. In particular, the sociability aspect of eating seems to be at the heart of the phenomenon of 'social eating' since it shows a substantial positive co-variation with the three social aspects of eating: social norms, social image, and traditions. In a similar way, Jackson and colleagues (2003) found social and compliance motives to be interrelated (see also Herman et al., 2003 for a comprehensive model of social influence on eating). Interestingly, the present data also suggest that sociability is positively correlated with the pleasure of eating. This association was also reported by Jackson and colleagues (2003). However, through the systematic assessment of eating motives, we found that the tendency to eat for social reasons was not only related to eating for pleasure, but also to visual appeal aspects of food. Thus, sociocultural motives appear to constitute a network of motives based on social and biological incentives for eating. On the contrary, health concerns typically promoted by public health interventions were comparably less interrelated with other motives. Specifically, they were related with body weight control and natural concerns (cf. Steptoe et al., 1995). Comparing these two interrelation clusters suggests that the latter is more motivated by an avoidance mindset, whereas the former is primarily motivated by an approach mindset. One might speculate that for sustainable eating behavior changes, health concerns need to be positively related to social and biological incentives for eating.

Relative importance of eating motives for food choice: Comparison between motives across groups

The question of which types of motives trigger food choice does not infer which are most influential. Comparing the different subsamples showed that the factorial structure was highly comparable across the groups. In terms of the relative importance of the 15 motives, commonalities as well as systematic differences emerged. Liking, Habits, Need \& Hunger, and Health were rated as triggering eating behavior fairly often. In contrast, Social Image, Social Norms, and Affect Regulation were seldom rated as a trigger for eating or food choice. This pattern is similar to the rank order found by Steptoe and colleagues (1995) with Sensory Appeal and Health being 
rated most important, while Mood, Ethical Concern, and Familiarity were rated least important. Likewise, Pleasure and Sociability were rated as being more important than Affect Regulation and Social Norms, as suggested by Jackson and colleagues (2003).

The greatest differences in the relative importance between motives emerged between women and men. Women demonstrated significantly higher means than men on 10 out of 15 TEMS scales. The difference was especially pronounced for affect regulation and body weight control reasons. Also, Steptoe and colleagues (1995) reported consistent gender differences with women having higher values on all food choice motives except Sensory Appeal and Familiarity. That women rated nearly every eating motivation as more frequently influencing eating behavior than men could be due to women being more preoccupied with food in general (Tapper \& Pothos, 2010).

A more specific pattern of differences in motives emerged for younger and older participants. Interestingly, younger participants gave more priority to palatable food than older participants, which could reflect a more 'short-term-oriented' eating style. In line with this reasoning, older participants gave more priority to 'long-termoriented' eating motives such as Health and Natural Concerns. This age difference in Health and Natural Concerns has been described before (Steptoe et al., 1995) and also seems intuitive since there is an absolute health benefit for ageing individuals and populations in adopting healthy diets (Darnton-Hill, Nishida, \& James, 2004). Furthermore, younger participants' eating behavior was also more often driven by Need \& Hunger, Pleasure, Convenience, Visual Appeal, and Affect Regulation, further supporting the idea that younger individuals are more often driven by short-term-related eating motives. Furthermore, younger participants seem to be more influenced by social norms and social image influences. Interestingly, in contrast to social norms and the desire to present oneself favorably to others by eating certain food items, sociability was an equally frequent endorsed reason for eating with both younger and older participants. Contrary to previous results (Steptoe et al., 1995), older participants' eating behavior was no more often driven by routine than younger participants'. Instead, they gave even less importance to Traditional Eating. Since changing existing routines is a big challenge in diet intervention, it is important to know that these routines are set already in young individuals.

Participants with a BMI lower than $25 \mathrm{~kg} / \mathrm{m}^{2}$ had significantly higher scale means for Liking, Health, and Need \& Hunger, whereas overweight or obese participants had significantly higher scale means for Weight Control, Affect Regulation, and Social Norms. This indicates that intuitive eating (Tylka, 2006) is greater in participants with a lower BMI. They eat more often because of physiological hunger while those with a higher BMI rely more on social norms and emotional cues. However, since our study was crosssectional, we do not know if eating motives, e.g. Health, cause certain BMIs or if BMI causes eating motives, e.g. Weight Control.

\section{Limitations}

The investigated eating motives were developed in an environment where one can choose between thousands of food products every day. Thus, future research needs to investigate how these eating motives apply to other environments in which food is scarce. Since the participants took part in online surveys on a voluntary basis, our samples were self-selected, which may have biased the results. That the vast majority of the participants had a high school degree and were probably of White European origin clearly limits the generalizability of the findings. Replicating the results in other samples and cultures is desirable (cf., Renner et al., 2008). Self-reported motives might not always reflect accurately the actual underlying motives for food choice. The complementary assessment of implicit motives should be subject to future research. Convergent validity was investigated through multiple-group invariance testing; however, validity was not assessed in relation to other measures. Furthermore, both the re-test-reliability of the TEMS as well as the relationship between eating motives and eating should be investigated in a prospective study. The latter would add evidence to causality concerning eating motives and body weight transitions.

\section{Conclusion}

Taken together, TEMS is a comprehensive measurement of why we eat what we eat. This allows for a conjoint assessment of eating motives and adds information to a definition of normal eating behavior. Although structural equality could be secured across gender, BMI, and age, clear differences in terms of the relative importance of the motives within the various subsamples emerged. Moreover, factorial correlations suggest that sociocultural motives such as sociability, social norms, traditions, and social image concerns relate to biological variables constituting a network of approach motives for eating. Conversely, health concerns, which are typically promoted by public health interventions, were specifically related with body weight control and natural concerns, indicating a network of avoidance motives. In order to trigger sustainable eating behavior changes, health concerns may need to be positively related to social and biological incentives for eating.

\section{References}

Aikman, S. N., Crites, S. L., \& Fabrigar, L. R. (2006). Beyond affect and cognition Identification of the informational bases of food attitudes. Journal of Applied Social Psychology, 36, 340-382. http://dx.doi.org/10.1111/j.0021-9029.2006. 00011.x.

Augustus-Horvath, C. L., \& Tylka, T. L. (2011). The acceptance model of intuitive eating. A comparison of women in emerging adulthood, early adulthood, and middle adulthood. Journal of Counseling Psychology, 58, 110-125. http:// dx.doi.org/10.1037/a0022129.

Bacon, L., \& Aphramor, L. (2011). Weight science. Evaluating the evidence for a paradigm shift. Nutrition Journal, 10, 9-21. http://dx.doi.org/10.1186/14752891-10-9.

Bollen, K., \& Long, J. (1993). Testing structural equation models. Newbury Park, CA: Sage.

Bortz, J., \& Döring, N. (2002). Forschungsmethoden und Evaluation für Human- und Sozialwissenschaftler (3. Aufl. ed.). Berlin: Springer.

Byrne, B. M. (2008). Testing for multigroup equivalence of a measuring instrument A walk through the process. Psicothema, 20, 872-882.

Cepeda-Benito, A., Gleaves, D., Williams, T. L., \& Erath, S. A. (2000). The development and validation of the state and trait food-cravings questionnaires. Behavior Therapy, 31, 151-173. http://dx.doi.org/10.1016/S0005-7894(00)80009-X.

Curran, P. J., West, S. G., \& Finch, J. F. (1996). The robustness of test statistics to nonnormality and specification error in confirmatory factor analysis. Psychological Methods, 1, 16-29. http://dx.doi.org/10.1037/1082-989x.1.1.16.

Darnton-Hill, I., Nishida, C., \& James, W. P. T. (2004). A life course approach to diet, nutrition and the prevention of chronic diseases. Public Health Nutrition, 7, 101-121. http://dx.doi.org/10.1079/PHN2003584.

Eertmans, A., Victoir, A., Notelaers, G., Vansant, G., \& Van den Bergh, O. (2006). The Food Choice Questionnaire. Factorial invariant over western urban populations? Food Quality and Preference, 17, 344-352. http://dx.doi.org/10.1016/ j.foodqual.2005.03.016

Fotopoulos, C., Krystallis, A., Vassallo, M., \& Pagiaslis, A. (2009). Food Choice Questionnaire (FCQ) revisited. Suggestions for the development of an enhanced general food motivation model. Appetite, 52, 199-208. http://dx.doi.org/ 10.1016/j.appet.2008.09.014.

Friedenberg, L. (1995). Psychological testing. Design, analysis, and use. Boston, MA: Allyn and Bacon.

Glaser, B. G., \& Strauss, A. L. (1967). The discovery of grounded theory. Strategies for qualitative research. Chicago: Aldine Publishing Company.

Gold, M. S., \& Bentler, P. M. (2000). Treatments of missing data. A Monte Carlo comparison of RBHDI, iterative stochastic regression imputation, and expectation-maximization. Structural Equation Modeling, 7, 319-355. http:// dx.doi.org/10.1207/s15328007sem0703_1.

Grunert, S. C. (1989). Ein Inventar zur Erfassung von Selbstaussagen zum Ernährungsverhalten. Diagnostica, 35, 167-179.

Herman, C. P., Roth, D. A., \& Polivy, J. (2003). Effects of the presence of others on food intake. A normative interpretation. Psychological Bulletin, 129, 873-886. http:// dx.doi.org/10.1037/0033-2909.129.6.873. 
Horn, J. L. (1965). A rationale and test for the number of factors in factor analysis. Psychometrika, 30, 179-185.

Horner, T.N., Jr. (1998). The development of the Cornell University Eating Motivation Trait Inventory. A questionnaire to characterize and quantify normal eating behavior. 58, ProQuest Information \& Learning, US. Retrieved from <http://www.redi-bw.de/db/ebsco.php/search.ebscohost.com/ login.aspx?direct=true\&db=psyh\&AN=1998-95012-160\&site=ehost-live > Available from EBSCOhost psyh database.

Hu, L.-T., \& Bentler, P. M. (1999). Cutoff criteria for fit indexes in covariance structure analysis. Conventional criteria versus new alternatives. Structural Equation Modeling, 6, 1-55. http://dx.doi.org/10.1080/10705519909540118.

Jackson, B., Cooper, M. L., Mintz, L., \& Albino, A. (2003). Motivations to eat. Scale development and validation. Journal of Research in Personality, 37, 297-318. http://dx.doi.org/10.1016/s0092-6566(02)00574-3.

Januszewska, R., Pieniak, Z., \& Verbeke, W. (2011). Food choice questionnaire revisited in four countries. Does it still measure the same? Appetite, 57, 94-98. http://dx.doi.org/10.1016/j.appet.2011.03.014.

Kaiser, H. F. (1960). The application of electronic computers to factor analysis. Educational and Psychological Measurement, 20, 141-151.

Kline, R. B. (2011). Principles and practice of structural equation modeling (3rd ed.). New York, NY US: Guilford Press.

Letarte, A., Dube, L., \& Troche, V. (1997). Similarities and differences in affective and cognitive origins of food likings and dislikes. Appetite, 28, 115-129. http:// dx.doi.org/10.1006/appe.1996.0069.

Lindeman, M., \& Stark, K. (1999). Pleasure, pursuit of health or negotiation of identity? Personality correlates of food choice motives among young and middle-aged women. Appetite, 33, 141-161. http://dx.doi.org/10.1006/ appe.1999.0241.

Lindeman, M., \& Väänänen, M. (2000). Measurement of ethical food choice motives. Appetite, 34, 55-59. http://dx.doi.org/10.1006/appe.1999.0293.

Macht, M., \& Simons, G. (2000). Emotions and eating in everyday life. Appetite, 35 65-71. http://dx.doi.org/10.1006/appe.2000.0325.

Mann, T. Tomiyama, A. J. Westling E, Lew, A. M. Samuels, B., \& Chatman, J. (2007) Medicare's search for effective obesity treatments. Diets are not the answer. American Psychologist, 62, 220-233. http://dx.doi.org/10.1037/0003066x.62.3.220.

Martins, Y., \& Pliner, P. (1998). The development of the food motivation scale Appetite, 30, 94. http://dx.doi.org/10.1006/appe.1997.0127.

Mehl, M. R., Vazire, S., Holleran, S. E., \& Clark, C. S. (2010). Eavesdropping on happiness. Well-being is related to having less small talk and more substantive conversations. Psychological Science, 21, 539-541. http://dx.doi.org/10.1177/ 0956797610362675.

Meule, A., Lutz, A., Vögele, C., \& Kübler, A. (2012). Food cravings discriminate differentially between successful and unsuccessful dieters and non-dieters. Validation of the Food Cravings Questionnaires in German. Appetite, 58, 88-97. http://dx.doi.org/10.1016/j.appet.2011.09.010.

O'Connor, B. P. (2000). SPSS and SAS programs for determining the number of components using parallel analysis and Velicer's MAP test. Behavior Research Methods, Instruments \& Computers, 32, 396-402. http://dx.doi.org/10.3758/ BF03200807.

Pollard, J., Kirk, S. F. L., \& Cade, J. E. (2002). Factors affecting food choice in relation to fruit and vegetable intake. A review. Nutrition Research Reviews, 15, 373-387. http://dx.doi.org/10.1079/NRR200244.

Pudel, V., Westenhöfer, J. (1989). Fragebogen zum Eßverhalten. Handanweisung. [Eating Inventory (German Version): Manual] Göttingen: Hogrefe.

Renner, B., Kwon, S., Yang, B.-H., Paik, K.-C., Kim, S. H., Roh, S., \& Schwarzer, R (2008). Social-cognitive predictors of dietary behaviors in South Korean men and women. International Journal of Behavioral Medicine, 15, 4-13. http:// dx.doi.org/10.1007/bf03003068.

Robinson, E., Tobias, T., Shaw, L., Freeman, E., \& Higgs, S. (2011). Social matching of food intake and the need for social acceptance. Appetite, 56, 747-752. http:// dx.doi.org/10.1016/j.appet.2011.03.001.

Roininen, K., Lähteenmäki, L., \& Tuorila, H. (1999). Quantification of consumer attitudes to health and hedonic characteristics of foods. Appetite, 33, 71-88. http://dx.doi.org/10.1006/appe.1999.0232.

Schupp, H. T., \& Renner, B. (2011a). Food deprivation. A neuroscientific perspective. In V. Preedy, R. Ross Watson, \& C. R. Martin (Eds.), International Handbook of Behavior, Food and Nutrition (pp. 2239-2257). New York: Springer-Press.

Schupp, H. T., \& Renner, B. (2011b). The implicit nature of the anti-fat bias. Frontiers in Human Neuroscience, 5. http://dx.doi.org/10.3389/fnhum.2011.00023.

Sproesser, G., Strohbach, S., Schupp, H., \& Renner, B. (2011). Candy or apple? How self-control resources and motives impact dietary healthiness in women. Appetite, 56, 784-787. http://dx.doi.org/10.1016/j.appet.2011.01.028.

Stein, J. A., Lee, J. W., \& Jones, P. S. (2006). Assessing cross-cultural differences through use of multiple-group invariance analyses. Journal of Personality Assessment, 87, 249-258. http://dx.doi.org/10.1207/s15327752jpa8703_05.

Statistische Bundesamt (2012a). Zahlen und Fakten. [available at <https:// www.destatis.de/DE/ZahlenFakten/ZahlenFakten.html>; cited 20.03.2012].

Statistische Bundesamt (2012b) Informationssystem der Gesundheitsberichterstattung des Bundes. [available at <https://www.gbebund.de/>; cited 20.03.2012].

Steptoe, A., Pollard, T. M., \& Wardle, J. (1995). Development of a measure of the motives underlying the selection of food. The food choice questionnaire. Appetite, 25, 267-284. http://dx.doi.org/10.1006/appe.1995.0061.
Stunkard, A. J., \& Messick, S. (1985). The three-factor eating questionnaire to measure dietary restraint disinhibition and hunger. Journal of Psychosomatic Research, 29, 71-83. http://dx.doi.org/10.1016/0022-3999(85)90010-8.

Tapper, K., \& Pothos, E. M. (2010). Development and validation of a food preoccupation questionnaire. Eating Behaviors, 11, 45-53. http://dx.doi.org/ 10.1016/j.eatbeh.2009.09.003.

Thompson, B. (2004). Exploratory and confirmatory factor analysis. Understanding concepts and applications. Washington, DC: American Psychological Association.

Thompson-Brenner, H., Glass, S., \& Westen, D. (2003). A multidimensional metaanalysis of psychotherapy for bulimia nervosa. Clinical Psychology: Science and Practice, 10, 269-287. http://dx.doi.org/10.1093/clipsy/bpg024.

Tomiyama, A. J., Mann, T., \& Comer, L. (2009). Triggers of eating in everyday life. Appetite, 52, 72-82. http://dx.doi.org/10.1016/j.appet.2008.08.002.

Tylka, T. L. (2006). Development and psychometric evaluation of a measure of intuitive eating. Journal of Counseling Psychology, 53, 226-240. http://dx.doi.org/ 10.1037/0022-0167.53.2.226.

Van Strien, T., Frijters, J. E., Bergers, G. P., \& Defares, P. B. (1986). The Dutch Eating Behavior Questionnaire (DEBQ) for assessment of restrained, emotional, and external eating behavior. International Journal of Eating Disorders, 5, 295-315. http://dx.doi.org/10.1002/1098-108x(198602)5:2<295::aid-eat2260050209> 3.0.co;2-t.

Velicer, W. F. (1976). Determining the number of components from the matrix of partial correlations. Psychometrika, 41, 321-327.

\section{Appendix A}

\section{German Version [Fragebogen zu den Motiven des Essens]}

Ich esse das, was ich esse,

Appetit

weil ich es lecker finde

weil ich Appetit darauf habe

weil es mir gut schmeckt

weil ich Lust darauf habe

weil ich es gerne mag

Gewohnheit

weil ich das regelmäßig esse

weil ich es gewohnt bin, das zu essen

weil ich es üblicherweise esse

weil es fester Bestandteil meiner Ernährung ist

weil es zu meiner täglichen Ernährung dazugehört

weil ich es kenne

Hunger

weil ich Energie brauche

weil es angenehm sättigend ist

weil es nicht schwer im Magen liegt

weil ich Hunger habe

Gesundheit

weil ich mich damit ausgewogen ernähre

weil es gesund ist

weil es mich fit hält (z. B. vital, leistungsfähig)

um meinen Bedarf an Nährstoffen, Vitaminen und Mineralstoffen zu decken

weil ich es gut vertrage

Einfachheit

weil es schnell zuzubereiten ist

weil es wenig Aufwand bedeute

weil es einfach zuzubereiten ist

weil ich es einfach und bequem kaufen kann

weil es gerade da ist (z.B. griffbereit oder wurde mir von jemandem angeboten)

Genuss

um es mir gut gehen zu lassen

weil ich mir etwas gönnen möchte

weil es gute Laune macht

um mich damit für etwas zu belohnen

weil es Spaß macht, das zu essen

Traditionen

weil es zu bestimmten Situationen dazugehört

aufgrund von Traditionen (z. B. Familientradition, Feste)

weil ich damit aufgewachsen bin

weil es gut zur Jahreszeit passt

Natürlichkeit

weil es naturbelassen ist (z. B. nicht gentechnisch verändert)

weil es unbelastet ist (z. B. keine Pestizide, Schadstoffe, Antibiotika)

weil es aus biologischer Landwirtschaft stammt

weil es aus fairem Handel komm

weil es die Umwelt wenig belastet (z. B. durch Produktion, Verpackung,

Transport) 


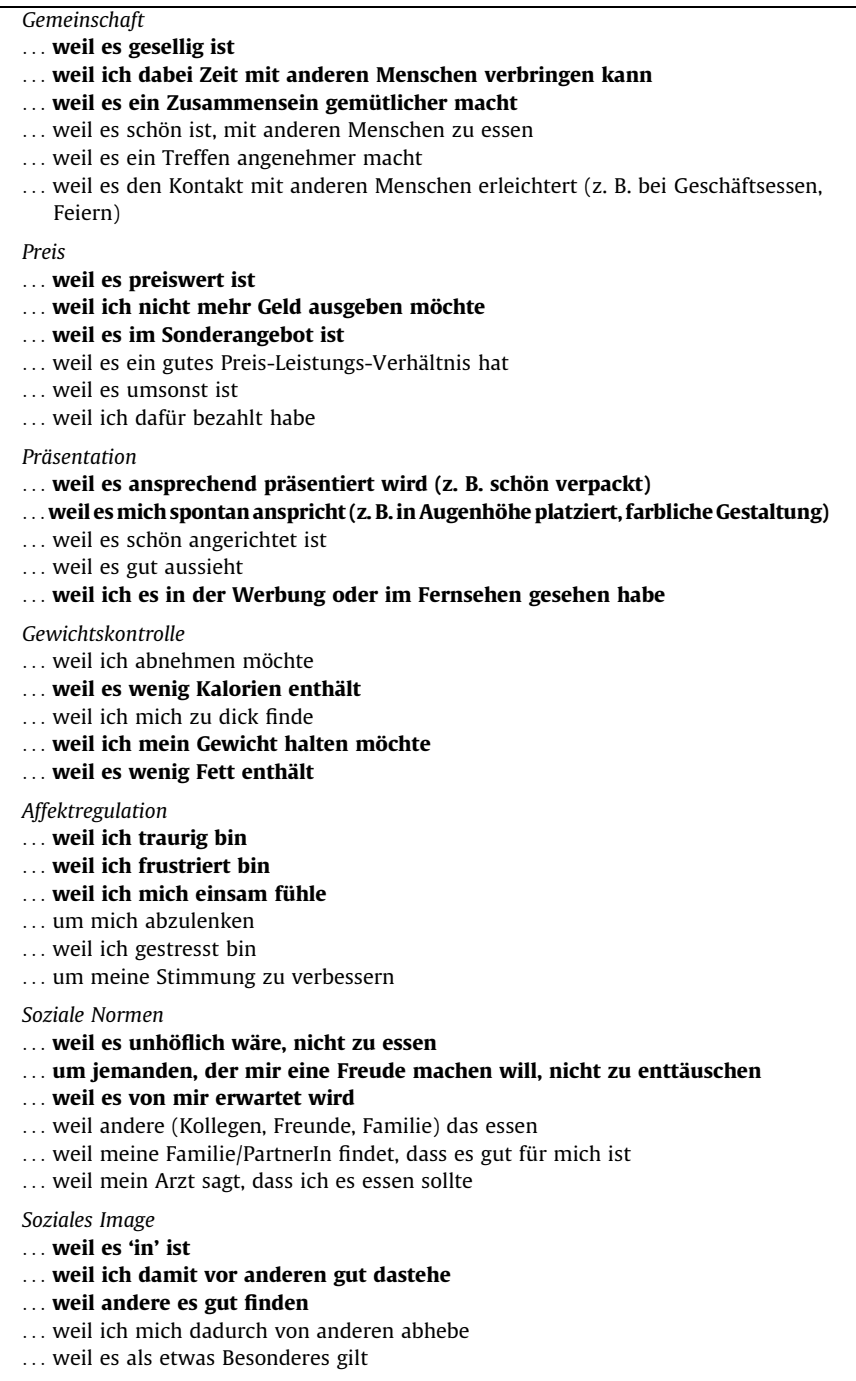

Note: Lines in boldface are items selected for the brief TEMS. Rating scale: [1] trifft nie zu; [7] trifft immer $z u$. 